\title{
Hidden penis: a rare case of delayed complication after a pelvic blunt trauma
}

\author{
Erika Palagonia, Daniele Castellani, Piero Ronchi, Lucio Dell'Atti, Andrea B. Galosi \\ Department of Urology, Marche Polytechnic University, Ancona, Italy \\ Correspondence to: Erika Palagonia. Department of Urology, Marche Polytechnic University, Ancona, Italy. Email: erika.palagonia@gmail.com.
}

\begin{abstract}
Penile dislocation following a traumatic pubic bone fracture is a very rare condition. Only a few cases are reported in the literature and the presentation mechanism is still not completely understood. The impact energy on the pelvis usually causes a displaced fracture with concomitant withdrawal of the pubic bone. The retraction of the pubic bone pulls the penis by its suspensory ligament leading to penile dislocation. We describe a rare case of a "hidden" penis 2 months after a blunt pelvic trauma following a motor vehicle accident. Clinical examination revealed a retracted penile skin. The penis was not visible, neither palpable in the expected position. Micturition took place by dripping urine from the opening of the prepubic skin where urine got trapped in the surrounding skin. He also complained of not having erections. A magnetic resonance imaging that showed invaginated penis, located in the anterior pelvic wall, adjacent to the right inguinal canal. Surgical repair was performed trough an inverted "V" suprapubic incision that allowed exploring the pubic area. The degloved penile shaft was identified and isolated from fibrotic adhesions to the surrounding tissue. The invaginated penile skin that was thin and retracted. The point of fixation was located deeply in the right pubic area where the subcutaneous tissue and skin were firmly attached to a spike of the fractured pubic bone. This adhesion was sharply resected and the penis and its skin were restored in their anatomical position. The suspensory ligament was partially detached. Erection was simulated using saline solution injection into the corpora cavernosa to exclude penile curvature. Postoperative course was uneventful. One year after surgery, the penis had a normal appearance without retraction and sexual function was completely restored. Our case pointed out the importance of genitalia evaluation by practitioners involved in the care of pelvic trauma patients.
\end{abstract}

Keywords: Pelvic trauma; penile dislocation; hidden penis; case report

Submitted Apr 20, 2021. Accepted for publication Jun 09, 2021.

doi: $10.21037 /$ tau-21-333

View this article at: https://dx.doi.org/10.21037/tau-21-333

\section{Introduction}

Penile dislocation following post-traumatic pelvic fractures is a rare condition, and it usually occurs early after the trauma (1-3). The impact energy on the pelvis usually causes a displaced fracture with concomitant withdrawal of the pubic bone. The retraction of the pubic bone pulls the penis by its suspensory ligament leading to penile dislocation. Sometimes the force of impact results in a traumatic circumferential degloving of the penis with separation of the shaft from its skin $(1,2)$. This kind of penis dislocation happens more frequently in children due to the laxity of the tissue, whilst internal retraction with consequent shortening of the penis is more frequent in adults $(4,5)$. We hereby present a case of delayed presentation of penile dislocation after pelvic trauma. We present the following article in accordance with the CARE reporting checklist (available at https://dx.doi.org/10.21037/tau-21-333).

\section{Case presentation}

A 52-year-old man was referred to us from a rehabilitation hospital for a "hidden" penis 2 months after a blunt pelvic trauma following a motor vehicle accident. He has been 

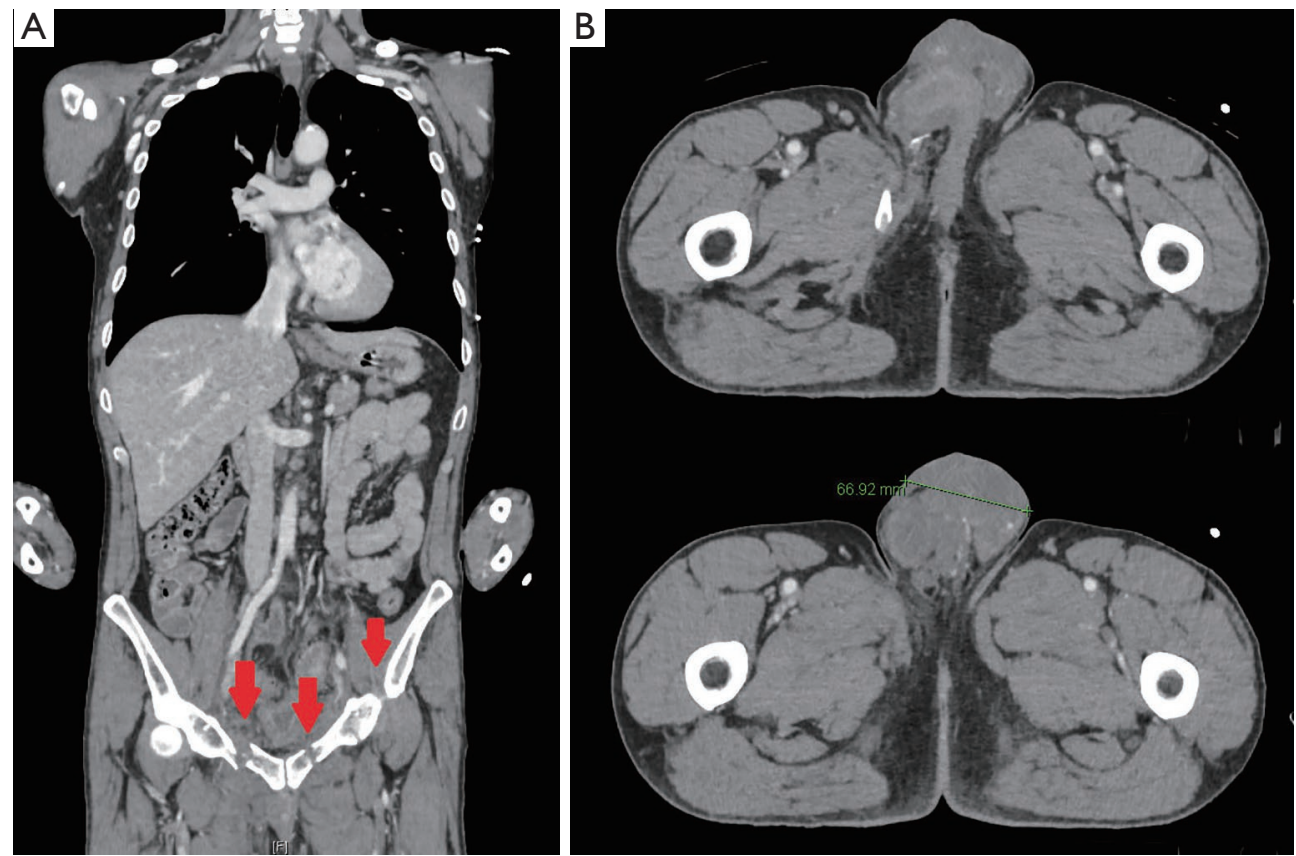

Figure 1 Enhanced computed tomography (CT) performed immediately after pelvic trauma. (A) Pubic bone fractures at CT scan. (B) Pelvic and testicular haematoma at CT scan.

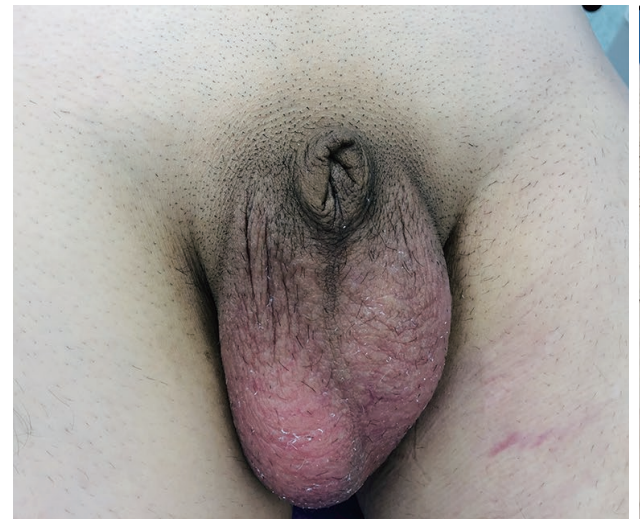

Figure 2 Clinical presentation with retracted penile skin and penis.

managed conservatively with bed rest. Sitting and standing positions were not allowed by orthopedics. Enhanced computed tomography (CT) performed at the time of accident showed multi-fragmentary displaced fractures of the right ileum and ischiopubic bone (diastasis), and multifragment displaced fracture of the left ischiopubic branch (Figure 1A). A large hematoma in both obturator fossa and inguinal-scrotal regions was also present (Figure 1B). The penis was dislocated in the subcutaneous tissue surrounded

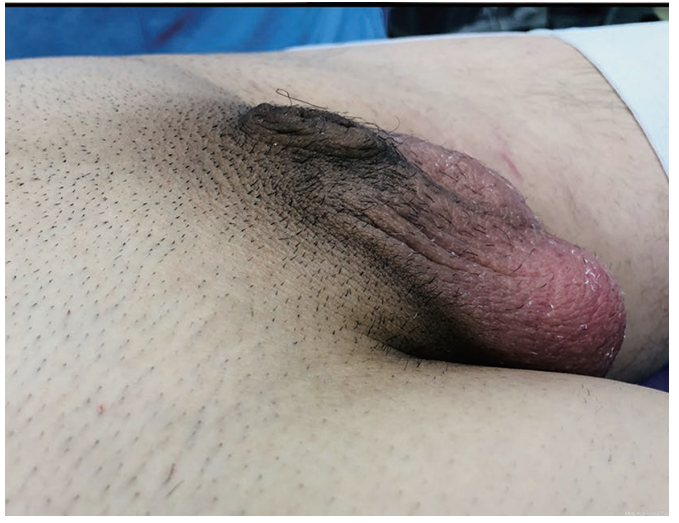

by a moderate hematoma (Figure $1 B$ ). However, penile dislocation was not reported by the radiologist. After reabsorption of pelvic edema, the patient complained of dribbling micturition. Micturition took place by dripping urine from the opening of the prepubic skin where urine got trapped in the surrounding skin (Figure 2). He also complained of not having erections. Clinical examination revealed a retracted penile skin. The penis was not visible, neither palpable in the expected position (Figure 2). Bladder 


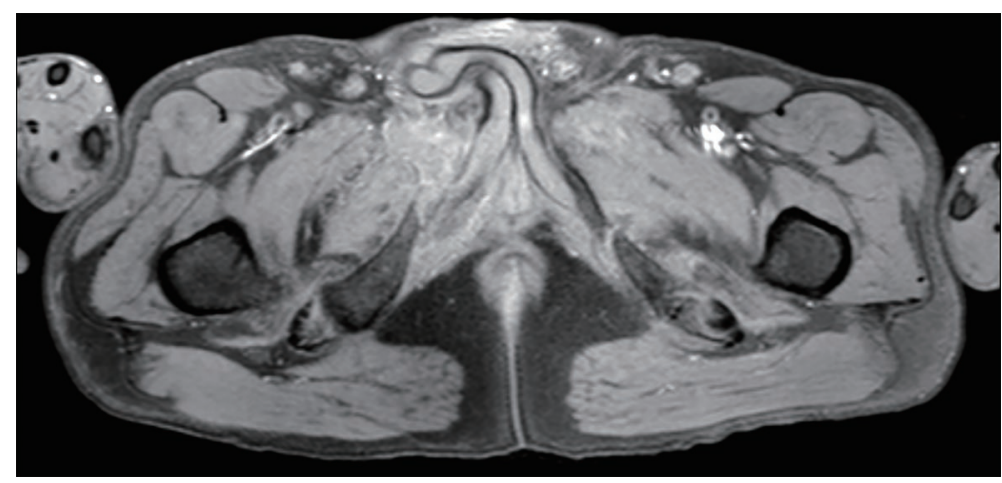

Figure 3 Pelvic magnetic resonance imaging showing the dislocated penis.
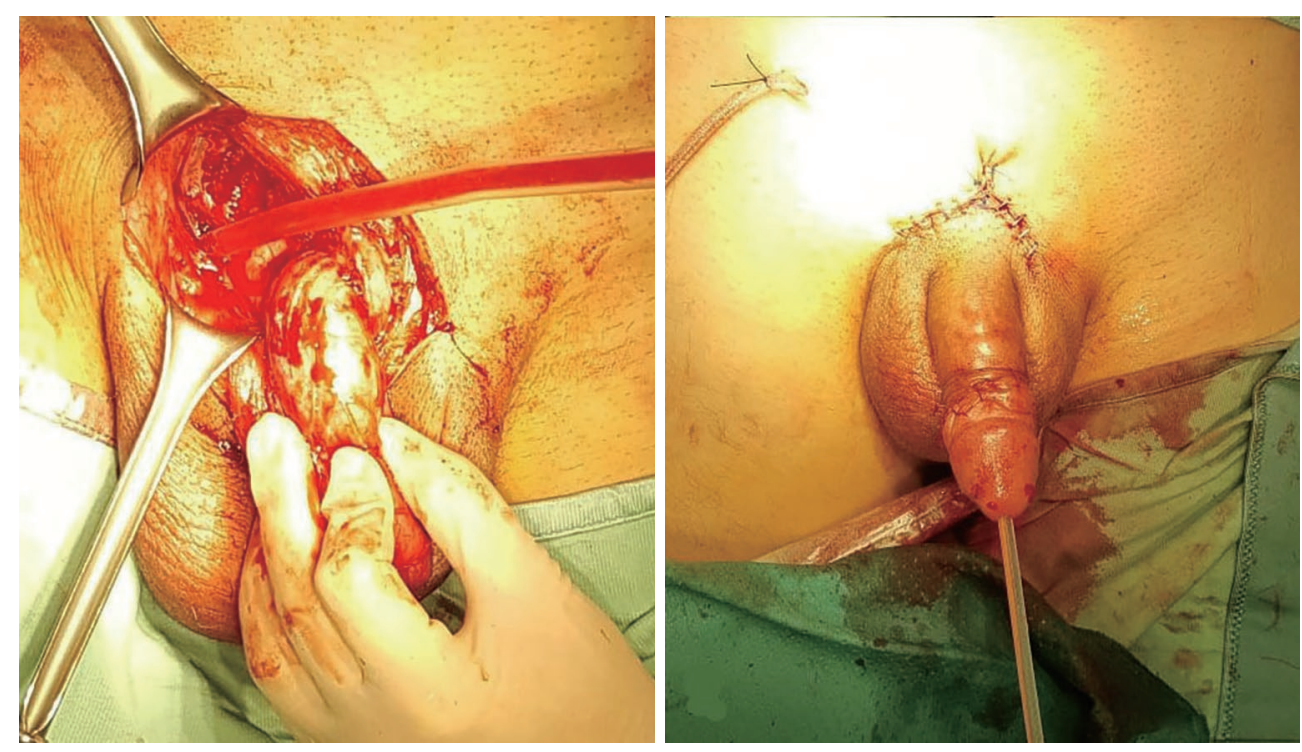

Figure 4 Surgical treatment.

catheterization was not possible. His body mass index was $23.04 \mathrm{~kg} / \mathrm{m}^{2}$. He underwent a lower abdomen magnetic resonance imaging that showed invaginated penis, which was located in the anterior pelvic wall, adjacent to the right inguinal canal (Figure 3).

Surgical repair was performed trough an inverted "V" suprapubic incision that allowed exploring the pubic area. The degloved penile shaft was identified and isolated from fibrotic adhesions to the surrounding tissue. This step was more easily than the isolation of the invaginated penile skin that was thin and retracted as an empty glove. This was done carefully to separate fibrosis to reach the deep point of fixation. This step was performed having regard to avoid damage to skin vascularization, subcutaneous tissue and to avoid skin necrosis, perforation, or infection. The point of fixation was located deeply in the right pubic area where the subcutaneous tissue and skin were firmly attached to a spike of the fractured pubic bone. These tissues were few millimeters close to the balano-preputial rim that was intact as well as the glans. This adhesion was sharply resected and the penis and its skin were restored in their anatomical position. The suspensory ligament was partially detached. Erection was simulated using saline solution injection into the corpora cavernosa to exclude penile curvature (Figure 4). The urethra had no lesions. After surgery, a moderate compressive dressing was applied for 2 days, and no postoperative complications occurred. After discharge, sitting position and normal micturition were allowed. 

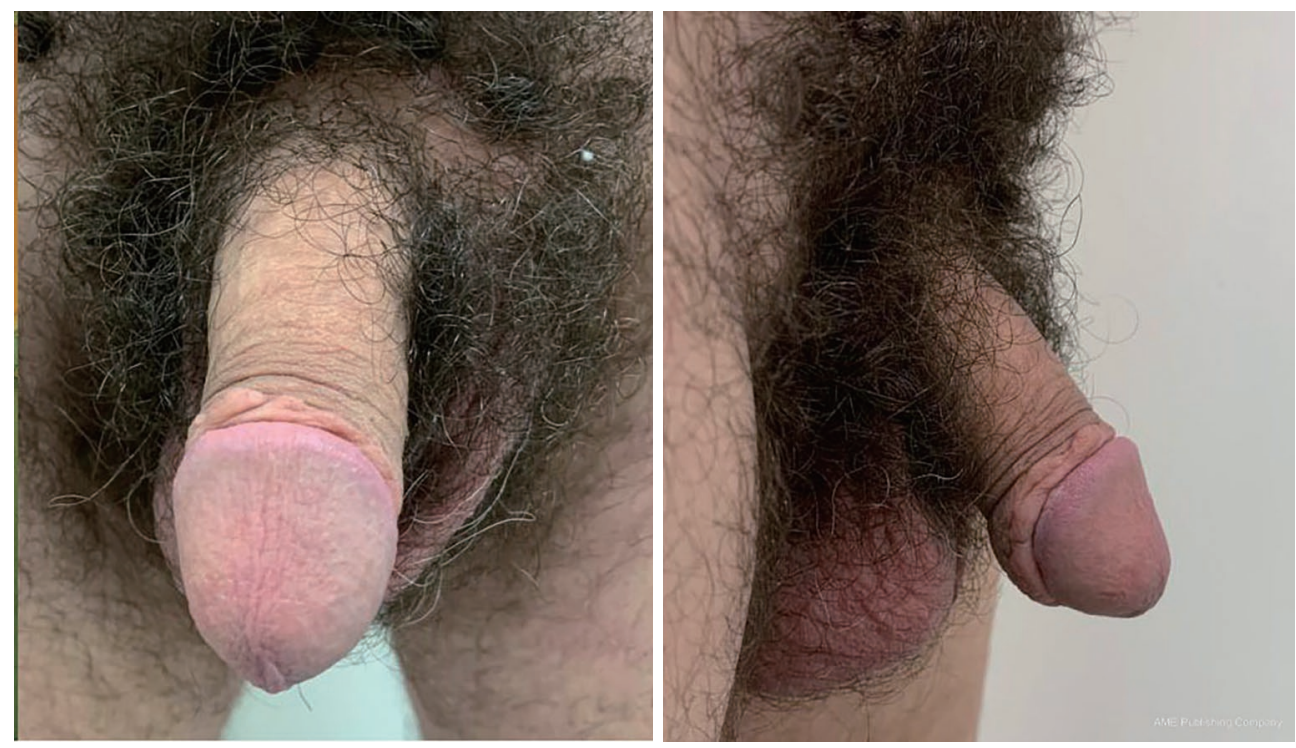

Figure 5 Results after one year follow-up.

One year after surgery, the penis had a normal appearance without retraction (Figure 5). Sexual function was completely restored. All procedures performed in studies involving human participants were in accordance with the ethical standards of the institutional and/or national research committee(s) and with the Helsinki Declaration (as revised in 2013). Written informed consent was obtained from the patient.

\section{Discussion}

Male external genitalia is frequently involved in blunt or penetrating pelvic trauma. The penis is usually involved with corpora cavernosa fracture and urethral lesion, while penile dislocation is very uncommon. The latter is usually present immediately after the trauma, with few reported cases (1-6). The displacement of the penis mainly occurs due to the strong impact energy, which can produce a traumatic degloving of the penis. The typical presentation is characterized by an empty penile skin and it is more frequent in children $(1,5)$. In this setting, the patient could be on urinary retention, and a suprapubic catheter may be necessary, or an emergency repair should be performed. Diastasis or fracture of the pubic symphysis is the second mechanism of penile dislocation due to the retraction of the suspensory ligament with subsequent shifting the penis inward $(2,4)$. This situation can be evident even years after the trauma and involves a complete or partial invagination of the penis from its anatomical site with shortening of the visible part and inability of penetration during sexual intercourse. In our patient, the retraction of the fractured pubic bone pulled the penis inward by the suspensory ligament, and, subsequently, the massive pelvic edema hidden the penis. The swelling of soft abdominal tissue completely hid the penis, leading to invagination of the shaft and its skin. Soon after pubis edema disappeared and the patient complained of dribbling micturition, penile dislocation became clinically apparent.

This late presentation of penile dislocation is very rare in adults. Indeed, adults with pelvic trauma typically present with a short penis and an invagination of the penile shaft soon after the trauma. Our case showed that a late presentation may occur even if the patient is still able to urinate. Urologists and practitioners involved in the care of pelvic trauma patients should keep this delayed presentation in mind to allow penile reallocation. A careful genitalia inspection should always be performed after a blunt pelvic trauma even in the absence of pain, haematuria, or urinary retention. A prompt surgical repair is mandatory to allow urinary and sexual restoration.

\section{Acknowledgments}

Funding: None. 


\section{Footnote}

Reporting Checklist: The authors have completed the CARE reporting checklist. Available at https://dx.doi. org/10.21037/tau-21-333

Conflicts of Interest: All authors have completed the ICMJE uniform disclosure form (available at https://dx.doi. org/10.21037/tau-21-333). The authors have no conflicts of interest to declare.

Ethical Statement: The authors are accountable for all aspects of the work in ensuring that questions related to the accuracy or integrity of any part of the work are appropriately investigated and resolved. All procedures performed in studies involving human participants were in accordance with the ethical standards of the institutional and/or national research committee(s) and with the Helsinki Declaration (as revised in 2013). Written informed consent was obtained from the patient.

Open Access Statement: This is an Open Access article distributed in accordance with the Creative Commons Attribution-NonCommercial-NoDerivs 4.0 International
License (CC BY-NC-ND 4.0), which permits the noncommercial replication and distribution of the article with the strict proviso that no changes or edits are made and the original work is properly cited (including links to both the formal publication through the relevant DOI and the license). See: https://creativecommons.org/licenses/by-nc-nd/4.0/.

\section{References}

1. Sahadev R, Jadhav V, Munianjanappa NB, et al. Penile Dislocation with Inversion: A Rare Complication of Blunt Pelvic Injury. J Indian Assoc Pediatr Surg 2018;23:90-2.

2. Simonis LA, Borovets S, Van Driel MF, et al. Erectile dysfunction due to a 'hidden' penis after pelvic trauma. Int J Impot Res 1999;11:53-5.

3. Shiraki IW, Trichel BE. Traumatic dislocation of the penis. J Urol 1969;101:186-8.

4. Masuda H, Azuma H, Segawa N, et al. Surgical correction of buried penis after traffic accident - a case report. BMC Urol 2004;4:6.

5. Lim MC, Srinivasan S, Teh HS, et al. Dislocation of the penis: a rare complication after traumatic pelvic injury. Singapore Med J 2015;56:e4-6.

6. CURR JF. Dislocation of the penis. Br J Urol 1946;18:66.
Cite this article as: Palagonia E, Castellani D, Ronchi P, Dell'Atti L, Galosi AB. Hidden penis: a rare case of delayed complication after a pelvic blunt trauma. Transl Androl Urol 2021;10(8):3524-3528. doi: 10.21037/tau-21-333 